\title{
CAMA
}

Centre for Applied Macroeconomic Analysis

\section{What's in a Second Opinion? Shadowing the ECB and the Bank of England}

\section{CAMA Working Paper 46/2013 July 2013}

\author{
Matthias Neuenkirch \\ RWTH Aachen University \\ Philipps-University Marburgand
}

\section{Pierre L. Siklos}

Wilfrid Laurier University

Viessmann European Research Centre and

Centre for Applied Macroeconomic Analysis (CAMA), ANU

\begin{abstract}
One way of evaluating how well monetary authorities perform is to provide the public with a regular and independent second opinion. The European Central Bank (ECB) and the Bank of England (BoE) are shadowed by professional and academic economists who provide a separate policy rate recommendation in advance of the central bank announcement. In this paper, we systematically evaluate this second opinion and find that, first, the shadow committee of the ECB tends to be relatively less inflation averse than the ECB. In contrast, the shadow committee of the BoE proposes a more hawkish monetary policy stance than the BoE. Second, consensus within a shadow committee is far easier to reach when there is no pressure to change the policy rate. Third, the ECB's shadow committee is more activist than the ECB's Governing Council and a larger degree of consensus within the former brings about a greater likelihood that the two committees will agree.
\end{abstract}




\section{Keywords}

Committee Behavior, Monetary Policy Committees, Shadow Councils, Taylor Rules

\section{JEL Classification}

E43, E52, E58, E61

\section{Address for correspondence:}

(E) cama.admin@anu.edu.au

The Centre for Applied Macroeconomic Analysis in the Crawford School of Public Policy has been established to build strong links between professional macroeconomists. It provides a forum for quality macroeconomic research and discussion of policy issues between academia, government and the private sector.

The Crawford School of Public Policy is the Australian National University's public policy school, serving and influencing Australia, Asia and the Pacific through advanced policy research, graduate and executive education, and policy impact. 


\title{
WHAT'S IN A SECOND OPINION? SHADOWING THE ECB AND THE BANK OF ENGLAND*
}

\author{
Matthias Neuenkirch, RWTH Aachen University \\ and Philipps-University Marburg
}

Pierre L. Siklos, Wilfrid Laurier University, CAMA (Centre for Applied Macroeconomic Analysis), Viessmann European Research Centre

\footnotetext{
* Research for this paper was carried out in part while the first author was a Visiting Scholar at the Viessmann Centre. The second author gratefully acknowledges financial assistance from a CIGI-INET research grant. Siklos is also thankful to the many central banks over the years where some of the data used in this study were collected. Comments on an earlier draft by Richard Burdekin, Michael Ehrmann, Charles Goodhart, Kent Matthews, Florian Neumeier, Michael Parkin, Bill Robson, David Smith, Peter Tillmann, two anonymous referees and the Journal Editor, are gratefully acknowledged. The authors also appreciate data support by Norbert Häring (Chair of the ECB shadow council). Versions of this paper were presented at the 2011 Money, Macro and Finance Research Group conference, the 2012 FinLawMetrics Conference, the 2012 ZEW Conference on Recent Developments in Macroeconomics, the Second World Congress of the Public Choice Societies, and research seminars at the Universities of Heidelberg and Münster. The data used in the study (and the appendix) will be available from the Central Bank Communication Network website (http://www.central-bank-communication.net/).
} 


\section{ABSTRACT}

One way of evaluating how well monetary authorities perform is to provide the public with a regular and independent second opinion. The European Central Bank (ECB) and the Bank of England (BoE) are shadowed by professional and academic economists who provide a separate policy rate recommendation in advance of the central bank announcement. In this paper, we systematically evaluate this second opinion and find that, first, the shadow committee of the ECB tends to be relatively less inflation averse than the ECB. In contrast, the shadow committee of the BoE proposes a more hawkish monetary policy stance than the BoE. Second, consensus within a shadow committee is far easier to reach when there is no pressure to change the policy rate. Third, the ECB's shadow committee is more activist than the ECB's Governing Council and a larger degree of consensus within the former brings about a greater likelihood that the two committees will agree.

Keywords: Committee Behavior, Monetary Policy Committees, Shadow Councils, Taylor Rules JEL codes: E43, E52, E58, E61

Pierre L Siklos, psiklos@wlu.ca

Matthias Neuenkirch, matthias.neuenkirch@rwth-aachen.de 


\section{Introduction}

Central to the conduct of 'good' monetary policy is credibility. Democratic accountability also demands that central banks explain their actions and provide sufficient information to enable the public to understand why certain policy decisions are taken. Monetary policy, however, is usually left to experts to implement and explaining to the general public why certain policy decisions are taken is not always straightforward. Nevertheless, at least until the financial crisis of 2008, the focal point of monetary policy was the manipulation of a policy rate instrument. This made it easier for central banks, and the public, to observe changes in the conduct of policy. Since that time, the interaction of historically low policy rates, combined with the implementation of various forms of policy easing, has complicated both the communication and the interpretation of monetary policy actions.

One way of independently assessing the value of monetary authorities' decisions is to provide the public with a second opinion. The European Central Bank (ECB) and the Bank of England (BOE) are both shadowed by a group of professional and academic economists. A shadow Monetary Policy Committee (SMPC) for the BoE has met since $1997^{1}$ while the shadow Governing Council (SGC) of the ECB has published its recommendations since $2002 .^{2}$ Their presence arguably provides the public with some checks and balances that are part and parcel of how democratic societies are expected to function.

Shadow monetary policy committees provide independent advice about the upcoming setting of the monetary policy instrument in their respective economies. Their task is not to predict what the central bank will do. Instead, these bodies aim to put forward their own independent assessment about the appropriate stance of monetary policy. In so doing, they

\footnotetext{
${ }^{1}$ A separate shadow committee of the BoE, the TIMES MPC, has operated since 2002 but, as this is written, we have not been able to compile sufficient data to undertake the kind of empirical study presented below. See, however, Koo, Paya and Peel (2012) who report that the TIMES MPC largely agrees with its BoE counterpart, based on only 18 observations.

2 To our knowledge, there are only six economies for which a 'second opinion' about monetary policy decisions is available: Australia, Canada, the euro area, New Zealand, the U.K., and the U.S. Moreover, with the exception of the U.S., there has been no attempt at evaluating the advice provided by shadow monetary policy committees. For several reasons, we focus on the shadow councils for the euro area and the U.K. First, as we explain below, the lessons from the U.S.'s shadow open market committee cannot be compared with those of the other shadow committees. Second, the time series for Australia (since 2011) and New Zealand (since 2012) are too short to evaluate these shadow councils in a systematic way. Canada's C.D. Howe's Monetary Policy Council is examined by Siklos and Neuenkirch (2013).
} 
provide an additional voice that informs both the central bank and the public about the suitability of the current stance of monetary policy. Stated differently, these groups can contribute to making monetary policy more accessible to the public. Moreover, the central bank may well respond to potentially dissenting views about its actions by seeking to improve how effectively it communicates to the public.

After describing how these shadow committees operate, and pointing out differences vis-àvis the central banks they shadow, we systematically evaluate the second opinion provided by the two shadow councils relying on three sets of tests. First, we estimate separate Taylor (1993)-type rules (TR) for both the shadow and central bank committees and compare them. Second, we examine the determinants of consensus within the committees, data availability permitting. Finally, we consider sources of disagreement between the policy rate recommendations and subsequent settings by the actual monetary policy committees.

The evidence suggests that there are a few systematic differences between shadow and actual committee decisions. First, the shadow committee of the ECB tends to be relatively less inflation averse than the ECB's Governing Council. In contrast, the shadow committee of the BoE proposes a more hawkish monetary policy stance than the Monetary Policy Committee. Differences between the shadow councils and the actual committees are particularly noticeable since 2011.

Second, we find that consensus within a committee is far easier to reach when there is no pressure to change the policy rate. Indeed, rises or falls in policy rates negatively affect consensus. Furthermore, departures from the consensus are apparent when the results are disaggregated according to whether the committee members are professional or academic economists.

Third, we are unable to explain differences in policy rate recommendations between the shadow and formal committees of the BoE based on observable characteristics at our disposal. However, the same is not true in the ECB's case. Indeed, we report strong evidence that the SGC is more activist than its counterpart. Only a greater degree of consensus within the SGC brings about a greater likelihood that the two committees will agree. 
The rest of the paper is organized as follows. Section 2 briefly explains the organization, role and functions of shadow committees and compares them to the actual decision making bodies. Section 3 summarizes the data and offers a few stylized facts. Section 4 presents the empirical specifications and highlights some of the challenges that emerge when interpreting the work of shadow committees. Section 5 describes the results. Section 6 concludes.

\section{Shadow Monetary Policy Committees}

The original idea for second guessing monetary policy possibly came from Karl Brunner and Alan Meltzer when, during the 1970s, they formed the Shadow Open Market Committee (SOMC) paralleling the U.S. Federal Reserve's own Federal Open Market Committee (FOMC). The SOMC was created in response to what 'monetarists' at the time perceived to be an illfated 'Keynesian' style policy of volatile money growth and persistent inflation (see Meltzer 2000). The original intention was to meet twice a year and to produce a policy statement as well as position papers on a wide variety of economic issues presented by committee members. ${ }^{3}$ Poole, Rasche and Wheelock (2011) revisit the advice given by the SOMC and conclude, relying on a New Keynesian style framework, that their monetarist advice would have yielded less inflation and milder output losses for the U.S. economy compared with the actual policy implemented by the Fed. However, the SOMC's work cannot be compared with the shadow committees considered in this paper as its primary aim is not to provide policy rate recommendations nor does the SOMC meet as often as the FOMC it was shadowing.

The shadow committees we investigate take as given the statutory mandate of the central banks they follow, and act accordingly. The Bank of England's remit is to achieve aim for $2 \%$ inflation while, in the ECB's case, the goal is close to $2 \%$ inflation in the euro area. ${ }^{4}$ For the ECB's shadow committee there is, however, some disagreement with that central bank's inflation objective (see below). Nevertheless, there is no indication that this could be a source of influence in members' recommendations nor is it clear whether the disagreement is about

\footnotetext{
${ }^{3}$ There were no committee meetings from 1998 to 2005 and after 2006 only the policy papers remained. Archival documents and other related materials from the reconstituted SOMC are available at http://shadowfed.org/.

4 The Bank of England's mandate can be found at http://www.bankofengland.co.uk/monetarypolicy/Pages/framework/framework.aspx while the ECB's stated price stability objective can be found at http://www.ecb.europa.eu/mopo/strategy/pricestab/html/index.en.html.
} 
the proper weight the ECB should attach to inflation or whether the stated inflation goal (see n.4) is inappropriate. Whether persistent differences, if any, in the recommendations of the central bank, and the committees that shadow them, stems from ideological factors, competence, or other factors such as differences in relative information sets or some underlying hidden policy agenda, we cannot determine. There exists a myriad factors that go into committee decisions. However, our findings do suggest that there are subtle differences of views about the conduct of monetary policy between different monetary policy experts. ${ }^{5}$

\subsection{Shadow Committee of the Bank of England}

The BoE obtained operational independence to set the course of monetary policy in 1997. The Monetary Policy Committee (MPC) was created as the vehicle used by the BoE to set the policy rate on a monthly basis. Members of the committee are individually accountable under the legislation governing the BoE's operations and mandate. The BoE's MPC consists of 9 members, four of whom are external members appointed by the Chancellor of the Exchequer. Minutes are released shortly after each meeting and these contain information about the views of individual members. The policy rate is announced after a vote has been taken based on a motion put forward by the Governor. Since March 2009 the motion includes not only a recommendation for the next Bank Rate setting but also a vote about the size and direction of quantitative easing (QE).

The SMPC examined in this study is an undertaking of the U.K. Institute of Economic Affairs (http://www.iea.org.uk/smpc) and was created in July 1997 shortly after the BoE became independent of the Treasury. As of this writing the SMPC consists of a total of 14 members who represent both professional and academic economists in the U.K. The SMPC meets either in person or electronically a few days before the MPC to provide its recommendation based on a

\footnotetext{
${ }^{5}$ An illustration of the potential role of ideology in policy making was suggested in private correspondence with Charles Goodhart, a former member of the MPC, and David Smith of the SMPC. Both pointed out the tendency for some of the members of the shadow committee to exhibit 'monetarist' leanings. Accordingly, the TR may not represent an accurate reflection of some of the members' thinking over time (also see Smith 2007). This suggests to us that persistent differences between the SMPC and the MPC may well emerge as a result of ideological differences. We are neither able to put an ideological label on each SMPC member nor do we have independent information on members' ages or educational background. In any event, monetarists will aspire to some form of price stability and will subscribe to the existence of a short-run trade-off that exists between inflation and the real side of the economy that underpins the TR.
} 
majority vote. When formulating its recommendation the MPC's symmetric inflation target is adopted.

Like its counterpart at the BoE, minutes of the meetings and individual comments are recorded and published. Organizers of the SMPC ensure that each meeting records 9 votes to match the number of votes at the BoE's MPC meeting. Table 1 provides a summary that compares the main features of both committees. Voting proceeds on the basis of a motion put forward (e.g., to hold the rate) but votes are cast in an unspecified order. Since July 2009, the SMPC also provide a separate vote or expression about the direction of QE.

Table 1: Shadow Monetary Policy Committee for the Bank of England

\begin{tabular}{lcc}
\hline & MPC & SMPC \\
\hline Statement & yes & yes \\
Voting Record & yes & yes \\
Minutes & yes & yes \\
Press Conference & no & no \\
Forecast & quarterly & no \\
\hline
\end{tabular}

\subsection{Shadow Committee of the European Central Bank}

In case of the ECB, monetary policy decisions are delegated to a Governing Council (GC) which meets since January 1999 to set the course of monetary policy on a monthly basis. The GC consists of an Executive Board (EB), made up of six members, and the Governors of the 17 euro area central banks (as of January 2011). Hence, potentially 23 members make monetary policy decisions. Nevertheless, the EB is responsible for monetary policy decisions and prepares the work of the GC for the policy rate decisions expressed in terms of the main refinancing rate (MRR). The ECB announces its monetary policy decision and a press conference is held shortly after the meeting. Between 1999 and 2001 there were two announcements per month although generally only one pertains to the actual policy rate setting. Beginning in 2002, only one announcement is made regarding the setting of the MRR. Minutes are not released in a 
timely manner ${ }^{6}$ and the ECB acknowledges that its decisions are based on consensus (e.g., see Moutot, Jung and Mongelli 2008).

The SGC publishes its recommendations in the German publication Handelsblatt (http://www.handelsblatt.com/politik/konjunktur/shadow-council/). The group was founded in 2002. The SGC meets approximately 1 week before the ECB announces its own monetary policy decision. The meeting is usually held via a telephone conference call (only the November meeting is a physical meeting) and the SGC consists of 15 academic and professional economists. While there is no voting as such, the recorded opinion of the SGC is based on a tally of recommendations made at the meeting with a journalist acting as a non-voting Chair. The SGC formulates its recommendations based on a slightly different mandate than the GC since most of its members consider that an inflation objective of two percent with a symmetric tolerance as more appropriate than the $\mathrm{GC}^{\prime}$ s asymmetric inflation objective.

Occasionally, commentary from some of the SGC members is recorded but there is no formal press release. The 'minutes' record various issues in the euro area and elsewhere that pre-occupy members of the SGC. A novel element of the SGC is that its members are encouraged to supply a current year and one year ahead forecast for inflation and real GDP growth in the euro area with the mean value for the group reported. In addition to the recommended current setting, SGC members have recently been providing an interest rate bias over a 3 month ahead horizon. This is a form of forward guidance that is not yet provided by the ECB. Finally, also on an irregular basis, an article is published that provides an early indication of the concerns that the SGC will discuss at its next meeting. Table 2 compares the main features of the GC with the SGC.

\section{Data and Stylized Facts ${ }^{7}$}

Data were collected at the monthly frequency from the respective shadow committee websites listed in the previous section with additional data collected from the websites of the BoE and the ECB. As explained below, we also employ inflation and real GDP growth forecasts

\footnotetext{
${ }^{6}$ Note that the GC's unattributed voting records will be released with a delay of 30 years.

7 We will post the data used in this study on the Central Bank Communication Network's website, http://www.central-bank-communication.net/.
} 
from The Economist's Poll of Forecasters in case of the U.K. Because of data limitations we are unable to begin the sample from the very first meeting of either shadow committee. Hence, the sample for the SMPC begins in January 2002 and ends with the December 2012 recommendation, yielding 103 observations. Similarly, the first observation for the SGC dataset is January 2006 and the sample also ends with the December 2012 MRR recommendation, resulting in 74 monthly observations.

Table 2: Shadow Monetary Policy Committee for the European Central Bank

\begin{tabular}{lcc}
\hline & GC & SGC \\
\hline Statement & yes & no (press release) \\
Voting Record & no & Yes \\
Minutes & no & no (press release) \\
Press Conference & yes & no \\
Forecast & quarterly & monthly \\
\hline
\end{tabular}

\subsection{Shadow Committee of the Bank of England}

Figure 1a plots the BoE's SMPC's recommended interest rate settings (solid line) against the actual ones set by the BoE (diamonds) while Figure $1 \mathrm{~b}$ shows the range of individual recommendations within the SMPC. There are some differences between the median recommendations of the BoE's SMPC and its MPC counterpart even though, typically, these are not large (e.g., 25 basis points). On average, the SMPC seems to favor higher interest rates than the MPC. In 16 out of the 19 cases where both committees disagree on the appropriate level of interest rates the SMPC recommended a higher rate than was actually adopted by the MPC.

Differences between both committees are small in part because of the practice of changing policy rates in increments of 25 basis points. Moreover, it appears that the upper and lower bound of individual policy rate recommendations is remarkably close to the median value of recommended policy rates. Both facts should come as no great surprise as each time the MPC sets the policy rate this always requires that the SMPC take as given the policy rate actually set by the MPC. Consequently, some SMPC members might be tempted to form their proposal possibly based on a policy rate level they may not a priori consider appropriate given prevailing 
economic conditions. ${ }^{8}$ Alternatively, members who disagreed with a previous MPC decision, on reflection, may find the BoE's arguments credible thereby removing the earlier disagreement. While the empirical work presented below cannot account for all of the complexities in the policy making process we do observe, for example, that shadow committee members either revise their recommendations in line with the current stance of the MPC or persist with their previously recommended policy rate setting. These observations are reflected in our indicators of committee consensus and disagreement. ${ }^{9}$ Finally, disagreement between both committees is mostly subdued ever since the target rate has reached the zero-lower bound of interest rates. Nevertheless, the SMPC voted six times for an increase in the Bank rate during that period.

Differences in policy rate recommendations between both committees are statistically significant relying on a forecast unbiasedness test. This is accomplished by asking how well SMPC recommendations are able to forecast for the MPC's interest rate decision based on an OLS estimate of the following specification:

$$
\text { MPC Target } \text { Rate }_{t}=\alpha+\beta \text { SMPC Proposal } t+\varepsilon_{t}
$$

The joint test of unbiasedness is based on the null hypothesis that $\alpha=0$ and $\beta=1$ and is rejected at the one percent significance level $\left(\mathrm{Chi}^{2}(2)=12.5^{* *}\right)$.

\subsection{Shadow Committee of the European Central Bank}

Figure 2a plots the ECB's SGC's recommended interest rate settings (solid line) against the actual ones set by the ECB (diamonds). Figure $2 \mathrm{~b}$ plots the range of individual recommendations made by the SGC. There are some differences, occasionally persistent but typically no more than 25 basis points, between the GC's policy rate settings and those recommended by their counterparts on the SGC. On average, however, the SGC seems to favor lower interest rates than the MPC. In 21 out of the 22 cases where both committees disagree on the appropriate level for the policy rate the SGC is proposing a lower rate than actually

\footnotetext{
${ }^{8}$ To some extent, this extends to the MPC which takes the last decision as given although not all of its members might have approved the chosen policy stance.

${ }^{9}$ It has been suggested to us that the incentives of shadow committee members differ from members who sit on the formal policy making committee. This may be true since, for example, the MPC members belonging to the BoE are individually accountable for their decisions. Moreover, the extent to which shadow members seek out visibility might also differ from their counterparts at the central bank.
} 
adopted by the GC. Finally, disagreement between both committees is subdued during the period October 2009 - March 2011. However, ever since the GC actively resumed changing interest rates in April 2011, the SGC has consistently recommended a lower policy rate level. Similar to the U.K. experience, forecast unbiasedness is rejected at the one percent significance level $\left(\mathrm{Chi}^{2}(2)=40.9^{* *}\right)$. Hence, SGC recommendations are not unbiased forecasts of the $\mathrm{GC}^{\prime} \mathrm{s}$ policy rate settings.

Since the SGC shadows a supra-national central bank it is worth considering the distribution of the SGC's membership by nationality as the country of origin may create a bias in one direction or another (see, for instance, Arnold 2006). By this metric, on average, almost $30 \%$ of SGC members are from Germany. ${ }^{10}$ As a consequence, we investigate the potential for German influence in the empirical work reported below. Finally, it is also interesting to note that, in contrast to the SMPC, a substantial plurality of the SGC's membership consists of professional economists. This could bias policy rate recommendations in favor of lower interest rates if, say, professional economists are doves relative to their counterparts based in academic institutions.

\footnotetext{
${ }^{10}$ That is, their affiliation places them in Germany. We have no way of knowing, however, whether they are German nationals. It is also worth noting that there is considerable committee membership from France, followed by members from other EMU countries. The membership of the SGC also includes almost $20 \%$ of non-euro area affiliated economists.
} 

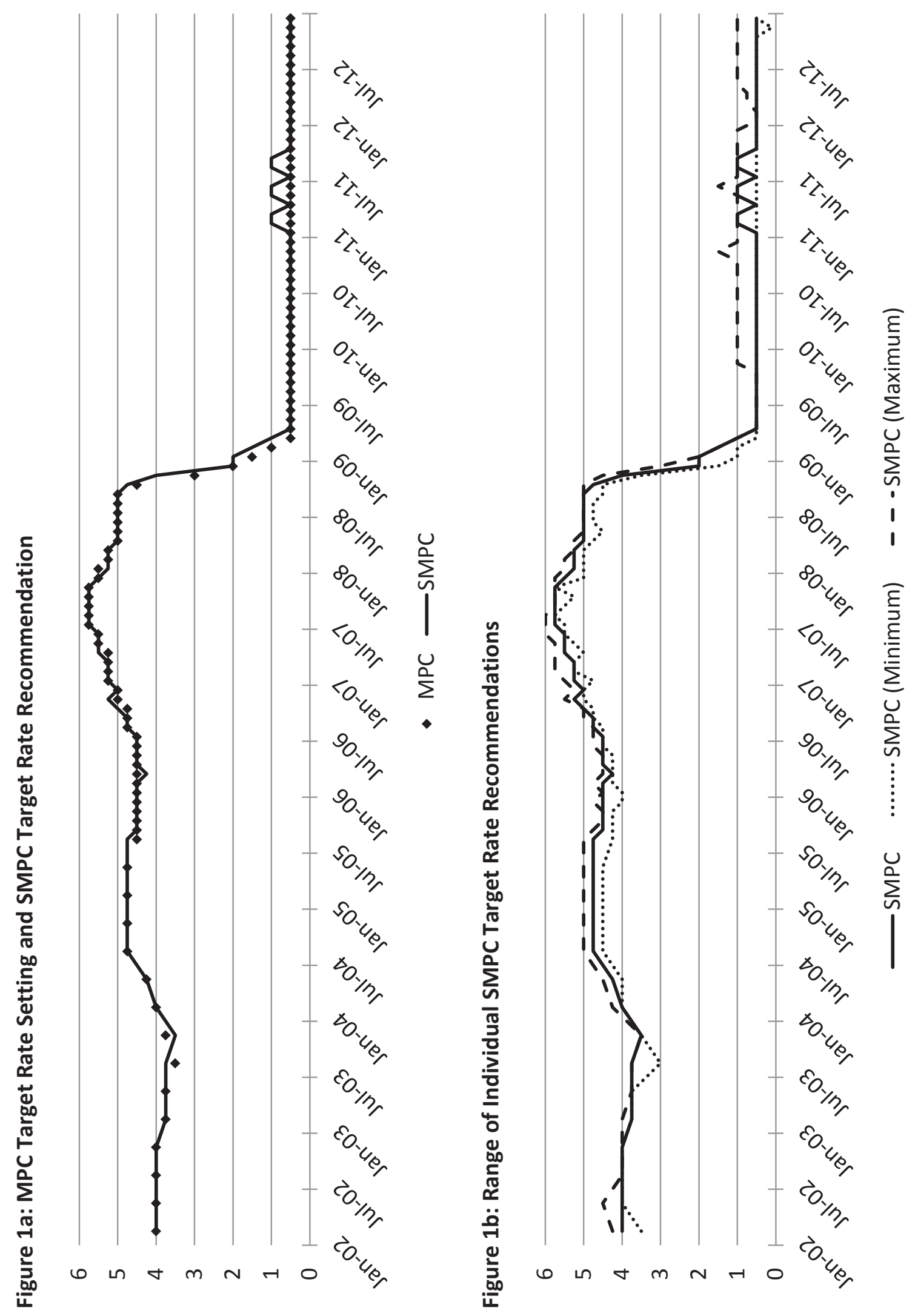

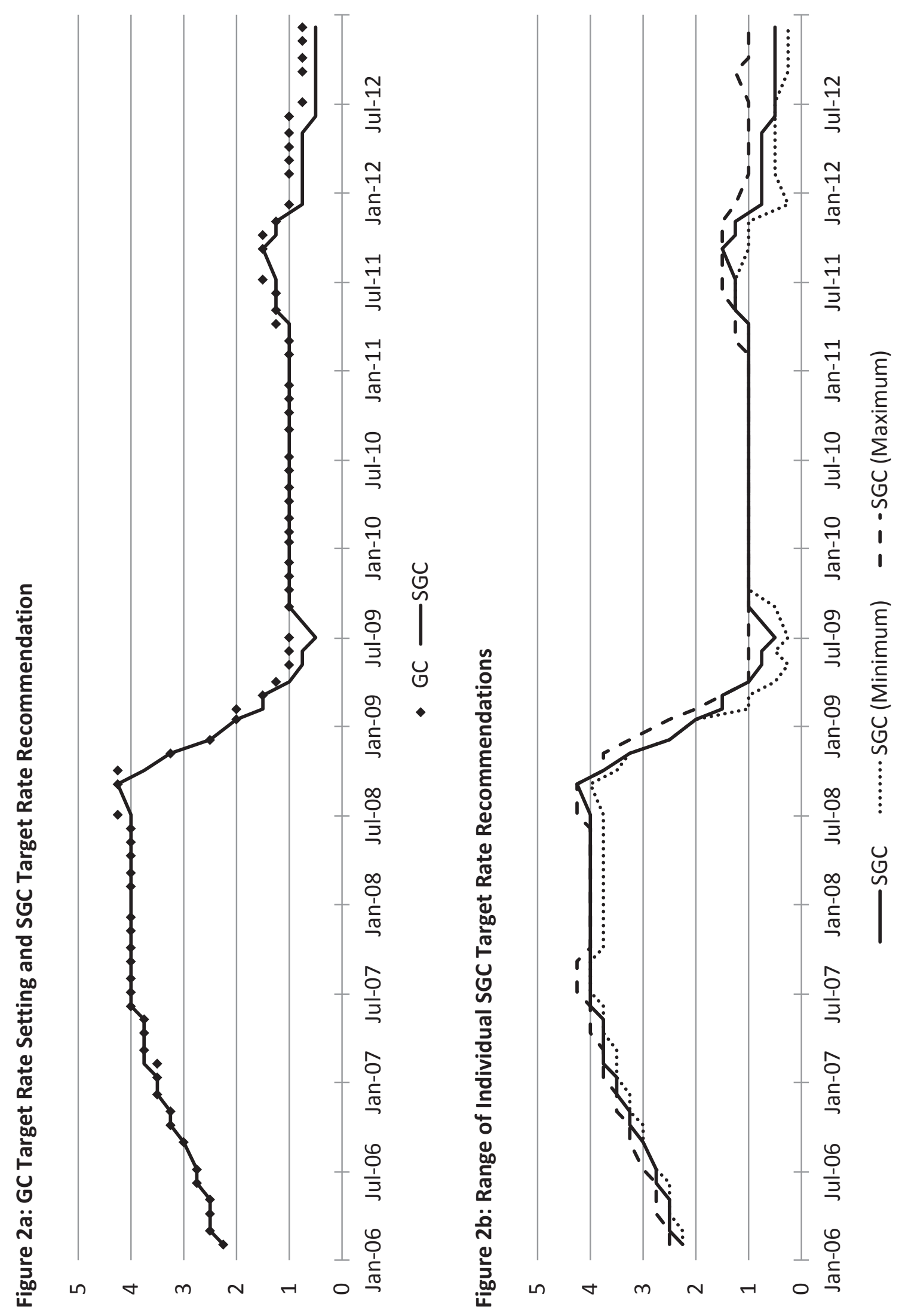


\section{Econometric Specifications}

\subsection{Monetary Policy Reaction Functions}

It is appropriate to estimate Taylor rules for several reasons. First, the literature has widely adopted the rule as a short-hand, and easy to implement, expression to evaluate the conduct of monetary policy. Second, it is unlikely that shadow council members focus on what the correct stance of monetary policy is on a full-time basis. ${ }^{11}$ Finally, there are considerable differences in relative accountability for policy mistakes. The stakes presumably are much higher for the central bankers though shadow members stand to have their reputations for expertise and good judgment tarnished if, in hindsight, they regularly propose inappropriate policy recommendations. Consequently, it seems useful to consider the kind of rule of thumb approach implicit in the application of TRs. Central bankers, while cautioning that the TR is instructive and must be flexibly implemented (e.g., Poole 2006), find that policy rules represent an effective monetary policy communication tool.

In what follows, we assume that the shadow committee and the corresponding central bank decision making bodies have the same information set. One might argue that central banks possess an information advantage over the public including the 'experts' who sit on the shadow committees. What is undoubtedly correct is that the resources available to decision-makers in central banks are comparatively larger than those available to most shadow committee members. ${ }^{12}$ However, actual policy rate decisions are based ultimately on committee members' judgment which is largely unobservable and is likely not based solely on estimates generated from a suite of models and scenarios. ${ }^{13}$

We estimate the following widely estimated TR-type specification, as proposed by Clarida, Gali and Gertler (1998):

$$
i_{t}^{\tau}=(1-\rho)\left(\alpha r_{t}+\beta_{0} \tilde{\pi}_{t+12 \mid t}+\beta_{1} \tilde{y}_{t+12 \mid t}\right)+\rho i_{t-1}^{C B}+\varepsilon_{t}
$$

\footnotetext{
${ }^{11}$ Nevertheless, members of shadow committees are involved in these kinds of deliberations due to their academic or professional interests in monetary policy and have the reputation and expertise to pronounce opinions on the subject on a regular basis.

${ }^{12}$ This comparative advantage may not extend to the external members of the BoE's MPC.

${ }^{13}$ There is one advantage that the MPC and the GC have over their shadow counterparts since there is a gap of several days between the announcement by the shadow committee and the central banks. We cannot, however, control for the impact of possible news arrival during this gap.
} 
Equation (2), for the most part, follows a standard $\mathrm{TR}^{14}$ with an interest rate smoothing parameter $(\rho)$ where the policy rate $\left(i_{t}^{\tau}\right)$ is set either by the central bank or recommended by the shadow committee. Both committees must set the current period policy rate according to the level set by the central bank in the previous period $\left(i_{t-1}^{C B}\right)$. Following Clarida (2012), the real interest rate $\left(r_{t}\right)$ is assumed to be time-varying and estimates are based on the 10 year real interest rate for the euro area and the U.K.

The determinants of the TR include an expected inflation gap $\left(\tilde{\pi}_{t+12 \mid t}\right)$ defined as the twelve month ahead inflation forecast minus the stated inflation target in the BoE's case ${ }^{15}$ and minus $2 \%$ in case of the ECB. ${ }^{16}$ The choice of an appropriate indicator for the unobservable twelve month ahead expected output gap $\left(\tilde{y}_{t+12 \mid t}\right)$ is less straightforward. Both central banks, as well as both shadow committees, focus on expected output growth rather than on the expected output gap in their communications (Gerlach 2007), probably in view of the difficulties of measuring the latter in real-time. Accordingly, we follow the recent literature (e.g., Gorter, Jacobs and de Haan 2008; Sturm and de Haan 2011) and use a simple deviation from a constant output growth trend (1.5\%) as proxy for the output gap. ${ }^{17}$ In case of the ECB, we resort to the mean inflation and real GDP forecast published as part of the SGC press release. For the U.K., we use the forecasts by The Economist. ${ }^{18}$

A well-known problem with specifications such as (2) is that right-hand side variables might be correlated with the error term leading to biased estimates of the coefficients. As a

\footnotetext{
${ }^{14}$ We chose not to add an exchange rate variable as, for instance, Fourçans and Vranceanu (2004) do in the ECB's case. Research on estimated as well as optimal TRs (e.g., see Clarida 2001, Collins and Siklos, 2004) suggest that adding this variable does not substantively change inferences based on the standard TR specification.

${ }^{15}$ The Bank of England changed its inflation measure and target during our sample period. Until the end of 2003, the (midpoint of its) inflation target was $2.5 \%$ annual growth of the Retail Price Index. Since 2004, the (midpoint of its) inflation target is $2 \%$ annual growth of the Harmonized Index of Consumer Prices.

${ }^{16}$ The ECB defines price stability as follows: "In the pursuit of price stability, the ECB aims at maintaining inflation rates below, but close to, $2 \%$ over the medium term."

${ }^{17}$ A widely followed practice in the relevant literature would suggest employing the Hodrick-Prescott (1997) (H-P) filter with the standard smoothing parameter of 14,400. However, this assumes perfect knowledge of all future expected output observations since it estimates trend output based on a two-sided filter (see also Sauer and Sturm 2007). Alternative formulations of the H-P filter address some of the drawbacks with the standard version of the filter but these alternatives remain more ad hoc than the definitions we rely upon in the empirical work below.

${ }^{18}$ As part of our robustness tests, we also employed the BoE's own forecasts and forecasts by Consensus Economics. Similarly, we also employed The Economist's and Consensus Economics data in the ECB case. Overall, the conclusions are unchanged.
} 
consequence, Equation (2) is estimated via the Generalized Method of Moments. ${ }^{19}$ An important consideration is the selection of valid instruments (e.g., see Siklos and Bohl 2009, and references therein). After considerable experimentation we chose lags of inflation, industrial production, a broad monetary aggregate, the overnight interest rate, and the nominal U.S. dollar exchange rate, as instruments.

In the empirical analysis below, we also have to contend with the fact that interest rates (i) have been at, or near, the zero-lower bound in the U.K. and the euro area for the last few years. As a result, monetary policy has recently shifted from interest rate decisions towards various forms of 'quantitative easing'. Nevertheless, differences between the respective shadow council proposals and policy rate decisions made by the central banks persist (see Figures 1a and 2a). Therefore, in what follows, we present two sets of TR estimates. One set covers the sample period before the introduction of QE in the U.K. (February 2002-December 2008) ${ }^{20}$ and the period before the interest rate pause in the euro area (January 2006-May 2009). A second set of estimates cover the full sample period (February 2002-December 2012 for the U.K. and January 2006-December 2012 for the euro area).

Since Orphanides (2001) it has been acknowledged that estimated policy rules based on revised data may give a misleading picture of the intended stance of monetary policy. In particular, policy makers, including the 'experts' who sit on shadow committees, base their decision on data at their disposal at the time they meet. Hence, it seems useful also to consider how estimates are affected by data available in real time. Generally, prices and interest rates are not subject to revisions. In contrast, output data are frequently revised. As Croushore (2011) points out, in a recent literature review, it is not only the most recent data that are revised. Instead, several years of data are revised as additional information arrives and each time new data are released. Furthermore, methodological or other processes in constructing time series can affect the previous history of data. Nowhere is this more noticeable than in the case of revisions to real GDP. As a result, those who advocate resort to real time data speak in

\footnotetext{
${ }^{19}$ Comparisons between GMM and OLS estimates suggest relatively few differences in the conclusions. OLS results are relegated to the Appendix.

${ }^{20}$ The introduction of QE was first proposed by the SMPC in January 2009 and announced by the MPC in its February 2009 Inflation Report.
} 
terms of vintages of data in reference to the fact that, each month or each quarter, several past observations of a particular series are revised thereby possibly significantly changing the interpretation of past economic performance. ${ }^{21}$

Since the MPC publishes its decisions about how much QE it wishes to implement since March 2009, while the SMPC explicitly votes on the amount of QE since July 2009, we can estimate a Taylor-inspired rule for setting the level of QE. The specification is as follows:

$$
Q E_{t}^{*}=\alpha Q E \text { Level }_{t-1}+\beta_{0} \tilde{\pi}_{t+12 \mid t}+\beta_{1} \tilde{y}_{t+12 \mid t}+\varepsilon_{t}
$$

$Q E_{t}^{*}$ is the latent continuous variable representing $\mathrm{QE}$ decisions. It is defined as a binary variable with 1 denoting the MPC decision (or SMPC proposal) to expand or extend QE and 0 denotes a decision (or proposal) to maintain the existing setting. ${ }^{22}$ The choice of a probit framework is a natural one since, unlike the MPC, the SMPC comes up with a directional proposal rather than recommending an exact amount of (additional) QE. Similar to Equation (2), both committees must base the current QE decision according to the level set by the central bank in the previous period $\left(Q E\right.$ Level $\left._{t-1}\right)$. The expected inflation gap $\left(\tilde{\pi}_{t+12 \mid t}\right)$ and the expected output gap $\left(\tilde{y}_{t+12 \mid t}\right)$ are defined as above.

The ECB's GC did not use QE or credit easing as means of injecting monetary stimulus. The only measures which are, to a limited extent only, comparable to BoE's QE are the decisions on the Securities Markets Programme in May 2010 and on the Outright Monetary Transactions in August 2012. The SGC did comment on buying government bonds on various occasions and, in general, was advocating such purchases in advance of the GC's decisions. However, since there are only some passing observations about unconventional monetary policies we cannot conduct a regression analysis similar to the one in Equation (3) in the case of the ECB. ${ }^{23}$

\footnotetext{
${ }^{21}$ As a result, real time data has a triangular structure such that, for example, the vintage for real GDP growth for a sample ending in 2011Q4 and a possibly entirely different time series will be used for the vintage of data that ends in 2012Q4. Also, see Croushore (2011, Table 1) for an illustration of the structure of real time data.

${ }^{22}$ There are no cases of reductions in QE (or reduction proposals).

${ }^{23}$ Likely a further consideration limiting incorporating an influence from recent ECB non-policy rate undertakings is the fact that SGC recommendations appear in a newspaper where space limitations come into play. In contrast, the BoE's SMPC publishes a separate document with extensive discussion in addition to a press release.
} 


\subsection{Consensus in the Shadow Councils}

Monetary policy committees are well known to be influenced by a need to achieve consensus (e.g., Sibert 2006). Therefore, we consider whether there are observables that can be used to explain how much consensus exists within the shadow committees. ${ }^{24}$ Consensus is defined as the share of recommendations identical to the median recommendation (in percent). We then estimate the following specification:

$$
\begin{gathered}
\text { Consensus }_{t}=\delta_{0}+\delta_{1} X_{t}+\mu_{t} \\
X_{t}=\left\{\text { MPC Votes }_{t-1}, \text { Pros }_{t}, \text { Ger }_{t}, \text { Cut }_{t}, \text { Rise }_{t}, \text { Size }_{t}\right\}
\end{gathered}
$$

MPC Votes $_{t-1}$ is the balance of votes in favor of the adopted policy stance by the MPC at its previous meeting (relevant only for the SMPC). It is included to test if a divergence of opinions in the MPC carries over to the next SMPC meeting. Pros $t_{t}$ and Ger $_{t}$ are the shares of professional economists and members based in Germany (relevant only for the SGC) who vote at each meeting. ${ }^{25}$ The specification allows for the possibility that consensus is achieved asymmetrically as between a rate cut $\left(\mathrm{Cut}_{t}\right)$ or rise $\left(\right.$ Rise $\left._{t}\right)$. Finally, $\mathrm{Size}_{t}$ measures the change in the policy rate in percent (e.g., 0.25). We can then ask whether larger proposed changes in the policy rate threaten consensus relative to smaller, more gradual changes. ${ }^{26}$ Equation (4) is estimated via OLS.

\subsection{Disagreement between the Shadow Councils and the Central Banks}

Disagreement between shadow and central bank policy making committees is likely. We explore sources of disagreement between the shadow council recommendations and the policy rate decisions taken by central banks. Disagreement is defined as a non-zero differential between the policy rate recommendation of the shadow committee and the monetary policy committee. Figures $1 \mathrm{a}$ and $2 \mathrm{a}$ suggest that disagreement tends to be more noticeable when

\footnotetext{
${ }^{24}$ In principle, one could estimate a TR for individual committee members. However, the average term of several members is brief enough to make this approach impractical.

${ }^{25}$ There is a long history of studies of the behavior of US's Federal Open Market Committee members and their individual preferences which is akin to the attempt here to assess the importance of the background of committee members. See, for example, Chappell, Havrilesky and McGregor (2000). There is also some recent evidence for the U.K.'s MPC (Berk, Bierut and Meade 2010). Note that in case of the SMPC, all members are based in the U.K.

${ }^{26}$ As a robustness test, we also considered a variable measuring the potential agenda-setting power of the SMPC's Chairman (the SGC has a non-voting Chairman). However, we did not find any significant impact which might not be that surprising since the Chairman was outvoted in 13 of 55 occasions (until December 2008).
} 
central banks enter a period of rising or falling policy rates. We examine if there is any empirical support for this form of asymmetric behavior (among other things) and estimate the following specification:

$$
\text { Agreement }_{t}^{*}=\kappa_{0}+\kappa_{1} X_{t}+\kappa_{1} \text { Consensus }_{t}+\eta_{t}
$$

Agreement $_{t}^{*}$ is the latent continuous variable representing differences between the actual and recommended policy rates. It is defined as a binary variable with $1(0)$ denoting agreement (disagreement) of both committees. Probit estimations shed light on the question of whether the probability of disagreement between the shadow and formal monetary policy committees is a function of the set of observables in vector $X_{t}$. Finally, we add the degree of consensus within the respective shadow council as additional explanatory variable.

\section{Results}

\subsection{Monetary Policy Reaction Functions}

Tables 3 and 4 present the estimates of Equation (2) for the BoE and the ECB, respectively. ${ }^{27}$ Examining first the case of the BoE, there are three notable findings from Table 3. First, the SMPC is more aggressive in fighting inflation than is the MPC. The differences in coefficients are statistically significant in the sample that omits the period of the financial crisis as well as in the full sample where the MPC is seen not respond to inflation at all. Second, in line with this impression, the MPC puts greater emphasis on output stabilization than the SMPC. Finally, the MPC effectively treats the real interest rate as zero in both samples, whereas the SMPC does not. As a result, the SMPC appears to be more hawkish than the MPC (also see Figure 1a).

\footnotetext{
${ }^{27}$ We relegate to the Appendix the case where the committees are assumed not to smooth interest rates. The main findings of the study are unaffected.
} 

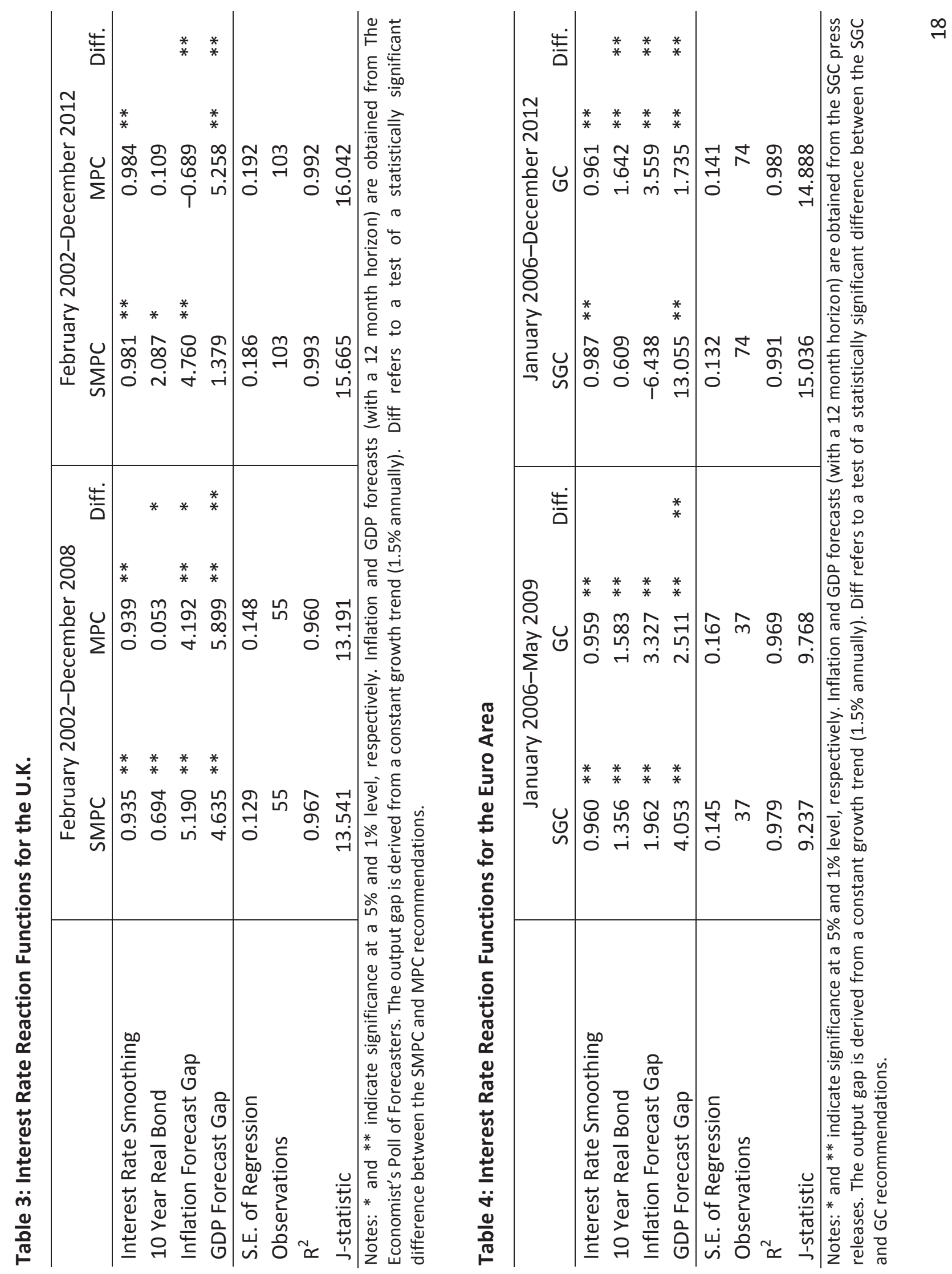
Turning to the case of the ECB examined in Table 4, we find, most remarkably, that the coefficients for the GC are almost unchanged in both samples considered. ${ }^{28}$ Hence, it appears that the ECB's reaction function has not changed since May 2009. Second, the SGC puts relatively less weight on inflation compared to the GC, in particular over the full sample. ${ }^{29}$ Third, the SGC is more responsive to output fluctuations than is the GC. Finally, the GC assumes a higher real interest rate than the SGC. Therefore, in contrast to the U.K. evidence, the shadow council is found to be more dovish than the central bank policy making body (see also Figure 1b).

Observed output an element in the calculation of the output gap, that is an essential ingredient in estimating Taylor rules, has been measured in a simplified fashion. ${ }^{30}$ We simply updated the last observation instead of taking into account that often a significant portion of the history of the real GDP time series is revised. We now ask: what is the central bank's and its shadow committee's response to both the inflation and output gap if, instead, we resort to data available at the time decisions are actually taken, that is, for each vintage in real time. As noted previously, each month or quarter the history of real GDP data are revised back several quarters. ${ }^{31}$ If revisions are substantial, for example, this may explain why central banks and their shadow counterparts may appear ex post to over or under-react to inflation or real economic developments. Figures 3 and 4 plot the steady state responses to the inflation and output gap for several vintages, beginning in 2006.

There are several notable results. First, there are considerable differences in the real time responses between the U.K. and the euro area. Responses are more volatile in the former than in the latter. Second, differences between the actual and shadow committees become quite apparent when we observe these in real time. In the case of the BoE, the shadow committee's

\footnotetext{
${ }^{28}$ Note that the coefficient for the output gap is slightly larger in the estimations using the full sample. However, the difference is statistically insignificant.

${ }^{29}$ Note that the coefficients for the full sample have to be interpreted with some caution. The episodes of unchanged interest rates lead to an increase in the SGC's interest rate smoothing parameter since and, therefore, to large steady-state values for the explanatory variables.

${ }^{30}$ Recall that the output gap is, typically, evaluated as the different between the (log) of the level of output and the (log) of potential output, where output in measured in terms of real GDP.

31 The number of quarters the data are revised can change over time depending, for example, on whether the series in question are revised in a comprehensive manner and the volume of information received by statistical agencies that prompt revisions. The IMF has a comprehensive list of references on the topic. See http://dsbb.imf.org/pages/dqrs/references.aspx.
} 
response to the output gap is relatively larger before the global financial crisis and smaller compared with the MPC's reaction to the GDP forecast gap after 2008. In contrast, the SMPC becomes much more hawkish about inflationary developments after 2009 than its counterparts at the MPC. Turning to the case of the ECB after 2011, the differences between the GC and the SGC are stark. Indeed, the SGC wants the euro area policy rate to decline even when the inflation gap is positive while positive output gap forecasts receives an increasingly larger response from the SGC. In contrast, after early 2009, the ECB's GC holds steadfast in its response to both inflation and the GDP forecast gap. ${ }^{32}$

Figure 3: Interest Rate Reaction Functions for the U.K. - Results in "Real Time”

MPC

SMPC

Inflation Forecast Gap
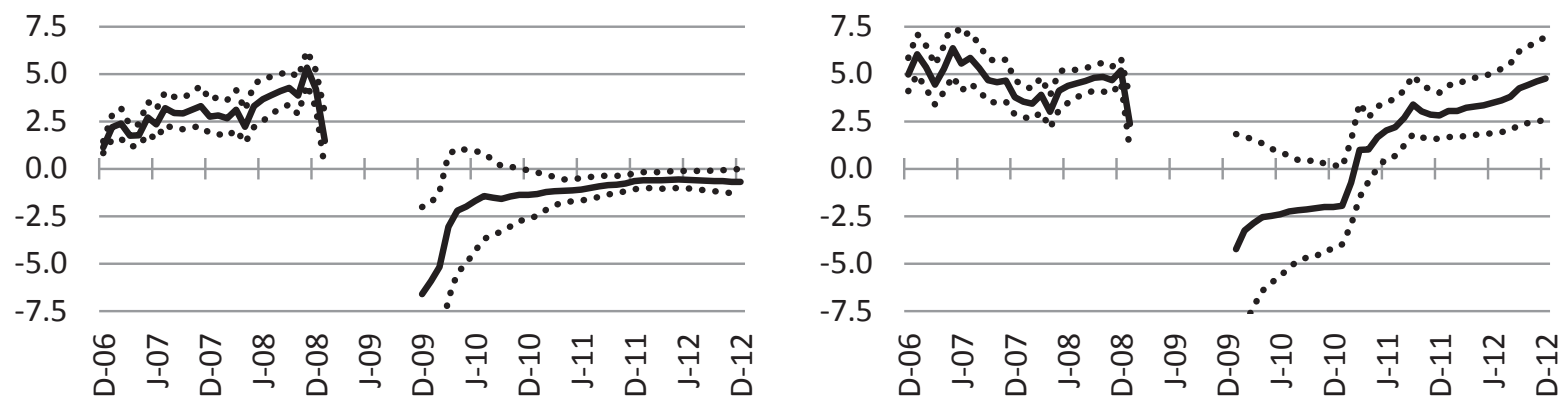

GDP Forecast Gap
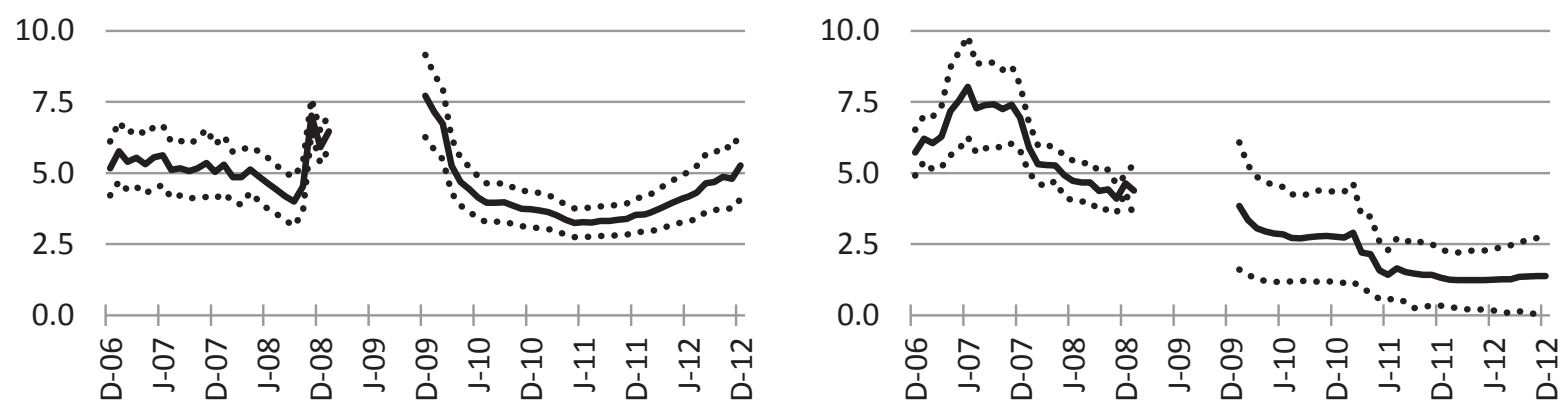

Notes: Solid lines show coefficients for the respective variable and vintage, whereas dotted lines represent the corresponding $95 \%$ confidence intervals. To facilitate the readability of the figures, steady-state coefficients are not reported if the coefficient for interest rate smoothing is $\geq 0.99$. Inflation and GDP forecasts (with a 12 month horizon) are obtained from The Economist's Poll of Forecasters. The output gap is derived from a constant growth trend (1.5\% annually).

\footnotetext{
32 Not shown, and relegated to an Appendix, are the real time estimates of the interest rate smoothing and real interest rate coefficients.
} 
Figure 4: Interest Rate Reaction Functions for the Euro Area - Results in "Real Time”

GC

SGC

Inflation Forecast Gap
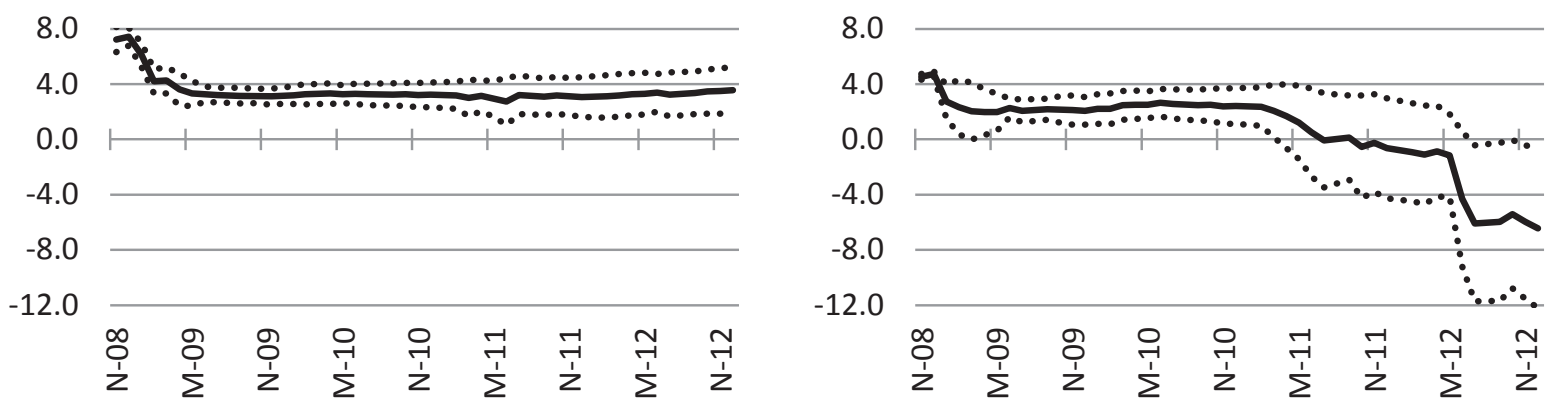

GDP Forecast Gap
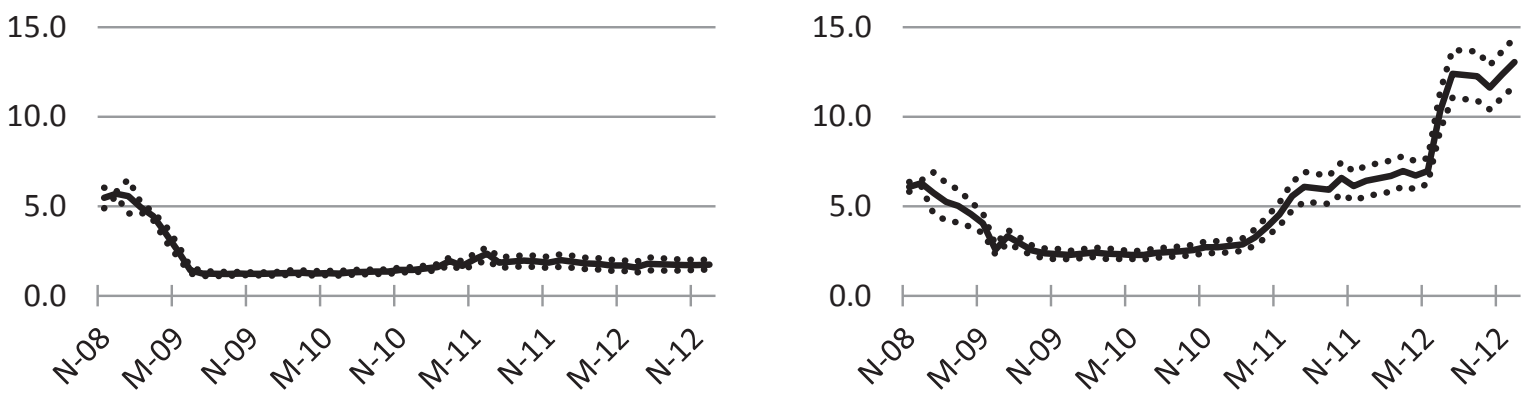

Notes: Solid lines show coefficients for the respective variable and vintage, whereas dotted lines represent the corresponding 95\% confidence intervals. Inflation and GDP forecasts (with a 12 month horizon) are obtained from the SGC press releases. The output gap is derived from a constant growth trend ( $1.5 \%$ annually).

As discussed previously, we are also able to estimate Taylor-type reaction functions for the MPC'S QE decisions and the SMPC'S QE proposals covering the period July 2009-December 2012. Table 5 shows the average marginal effects for the likelihood of expanding or extending QE (category 1) versus maintaining the policy at current levels (category 0 ).

The SMPC is more relatively cautious in proposing expansion or an extension of QE than the MPC. This is reflected in the finding that a higher current level QE decreases the probability of proposing another expansion/extension. Second, the SMPC also takes into account how inflation expectations evolve since, when these exceed the BoE's inflation target, the likelihood of additional QE falls. In contrast, the MPC seemingly ignores this variable as we find a counterintuitive positive sign. Third, both committees react to output fluctuations in a similar manner. A higher output gap decreases the probability of additional QE. Mirroring its policy 
rate recommendations, the SMPC is generally more hawkish about QE than its counterparts at the MPC.

Table 5: Quantitative Easing Reaction Function for the U.K.

\begin{tabular}{lrrr}
\hline & SMPC Proposal & MPC Decision & Diff. Sign. \\
\hline QE Level Lag & $-0.006^{* *}$ & $0.001^{*}$ & $* *$ \\
Inflation Forecast Gap & $-0.292^{* *}$ & $0.365^{* *}$ & $* *$ \\
GDP Forecast Gap & $-0.309^{*}$ & $-0.488^{* *}$ & \\
\hline Observations & $42^{* *}$ & $42^{* *}$ & \\
LR Statistic & $16.050^{* *}$ & $43.610^{* *}$ & \\
Pseudo Log-Likelihood & $-13.555^{2}$ & $-7.582^{*}$ & \\
Pseudo R & 0.522 & 0.686 & \\
Correct Predictions & 36 & 42 & \\
\hline
\end{tabular}

Notes: Sample period is July 2009-December 2012. Table shows average marginal effects for the likelihood of expanding or extending QE (category 1 ) versus maintaining the current level (category 0 ). ${ }^{*}$ and ${ }^{* *}$ indicate significance at a $5 \%$ and $1 \%$ level, respectively. Inflation and GDP forecasts (with a 12 month horizon) are obtained from The Economist's Poll of Forecasters. The output gap is derived from a constant growth trend (1.5\% annually). Huber (1967)/White (1980) robust standard errors are used. Diff refers to a test of a statistically significant difference between the SMPC and MPC recommendations.

\subsection{Consensus in the Shadow Councils}

The TR specifications considered so far are unable to deal with the question of what drives differences in views about policy rate recommendations. Whereas the ECB favors the consensus view of monetary policy decision-making, the BoE's governance model permits disagreements to be aired in public. Accordingly, Table 6 provides estimates of the determinants of consensus building factors inside each shadow committee relying on Equation $(4) .^{33}$

The share of professionals on the committee has a significant influence on consensus in policy rate settings for the SMPC for the shorter sample considered. However, the level of consensus achieved in the immediately previous MPC meeting does not play a significant role. ${ }^{34}$

\footnotetext{
${ }^{33}$ We also estimated equation (2) for the most dovish and most hawkish proposals made at each committee meeting (these are not always the same individuals). Hawks indentified in this manner react more strongly to inflation than their dovish counterparts, as one would expect a priori. Details are relegated to the Appendix. Unfortunately, there are relatively few observations consisting of individuals who are continuously hawkish or dovish.

${ }^{34}$ Estimates of equation (4), without a lagged term, does not lead to a statistically significant change in the other coefficients nor to a drop in the $\mathrm{R}^{2}$.
} 
Disagreement within the MPC does not carry over to the SMPC. Moreover, while consensus is always lower when rates change as opposed to when they remain unchanged, rate rises versus rate reductions do not appear to make a difference (small sample: $\mathrm{Chi}^{2}(1)=1.51$; full sample $\left.\mathrm{Chi}^{2}(1)=1.88\right)$. Finally, the contemplated size of the policy rate change is statistically insignificant.

Table 6: Consensus within the Shadow Councils

\begin{tabular}{l|cc|cc}
\hline & \multicolumn{3}{|c|}{ U.K.'s SMPC } & \multicolumn{2}{c}{ Euro Area's SGC } \\
& Feb 02-Dec 08 & Feb 02-Dec 12 & Jan 06-May 09 & Jan 06-Dec 12 \\
\hline Constant Term & $0.585^{* *}$ & $0.569^{* *}$ & $0.943^{* *}$ & $0.686^{* *}$ \\
Last MPC Consensus & $-0.034^{*}$ & 0.192 & - & - \\
Share of Germans & - & - & -0.346 & -0.362 \\
Share of Professionals & $0.434^{* *}$ & $0.008^{*}$ & -0.142 & $0.366^{* *}$ \\
\hline Proposal: Cut & $-0.324^{*}$ & $-0.300^{* *}$ & $-0.676^{* *}$ & $-0.672^{* *}$ \\
Proposal: Hike & $-0.205^{* *}$ & $-0.191^{* *}$ & $-0.300^{* *}$ & $-0.258^{* *}$ \\
Proposal: Absolute Size & $0.106^{* *}$ & $0.082^{*}$ & $1.119^{* *}$ & $0.902^{* *}$ \\
\hline S.E. of regression & 0.169 & 0.162 & 0.150 & $0.145^{*}$ \\
Observations & 55 & 103 & 37 & 74 \\
$\mathrm{R}^{2}$ & 0.336 & 0.279 & 0.121 & 0.542 \\
\hline
\end{tabular}

Notes: ${ }^{*}$ and ${ }^{* *}$ indicate significance at a $5 \%$ and $1 \%$ level, respectively. Newey-West (1987) standard errors are used.

Results are slightly different for the SGC. Rate cuts create relatively more disagreement among SGC members than rate hikes (small sample: $\mathrm{Chi}^{2}(1)=4.89 *$; full sample $\mathrm{Chi}^{2}(1)=$ $16.78^{* *}$ ) although both have the effect of reducing the degree of consensus in the committee. Moreover, the size of the proposed policy rate change also affects how much consensus exists in the committee. Hence, larger changes signal more agreement among committee members. However, it is likely that these results reflect the rapid reductions in policy rates in the aftermath of the Lehman bankruptcy. Finally, the share of professionals in the SGC increases consensus in the full sample period, whereas the share of Germans on the committee has no statistically significant influence. 


\subsection{Disagreement between the Shadow Councils and the Central Banks}

Next, we examine the sources of disagreement between the shadow and formally constituted monetary policy committees using Equation (6). ${ }^{35}$ Table 7 provides the average marginal effects for the likelihood of the central bank agreeing (category 1) or disagreeing (category 0) with the shadow council.

Table 7: Disagreement between the Shadow Councils and the Central Banks

\begin{tabular}{l|cc|rc}
\hline & \multicolumn{2}{|c|}{ U.K.'s SMPC } & \multicolumn{2}{c}{ Euro Area's SGC } \\
& Feb 02-Dec 08 & Feb 02-Dec 12 & Jan 06-May 09 & Jan 06-Dec 12 \\
\hline Consensus & -0.075 & 0.031 & $0.394 * *$ & $0.543 * *$ \\
Last MPC Consensus & 0.438 & 0.243 & - & - \\
Share of Professionals & 0.041 & 0.082 & $-1.031 *$ & -0.447 \\
Share of Germans & - & - & 2.237 & 0.424 \\
\hline Proposal: Cut & -0.347 & -0.135 & $-1.081 * *$ & -0.198 \\
Proposal: Hike & $-0.285 *$ & -0.194 & $-0.847 * *$ & -0.115 \\
Proposal: Absolute Size & -0.014 & -0.307 & $2.082 * *$ & 0.002 \\
\hline Observations & 55 & 103 & 37 & 74 \\
LR Statistic & $50.170 * *$ & $53.180 * *$ & $790.850 * *$ & $46.350 * *$ \\
Pseudo Log-Likelihood & -20.235 & -34.748 & -6.779 & -19.723 \\
Pseudo R & 0.225 & 0.294 & 0.748 & 0.562 \\
Correct Predictions & 42 & 88 & 34 & 67 \\
\hline
\end{tabular}

Notes: Table shows average marginal effects for the likelihood of the central bank agreeing (category 1) or disagreeing (category 0 ) with the shadow council recommendation. ${ }^{*}$ and ${ }^{* *}$ indicate significance at a $5 \%$ and $1 \%$ level, respectively. Huber (1967)/White (1980) robust standard errors are used.

First, we consider the U.K. case. The results reveal that it is difficult to explain a large portion of the variation in differences between the SMPC and the MPC based on the variables deemed to influence disagreement between the two committees. The only (marginally) significant coefficient is for rate hike proposals in the small sample which reduce the likelihood that both committees agree with each other.

The specifications are considerably more informative when euro area monetary policy is considered (but only in the January 2006-May 2009 sample). The ECB's shadow is contrasted with the formally constituted GC. Disagreement between the two committees is found to be

\footnotetext{
${ }^{35}$ An estimation of Equation (6) without the variable 'Last MPC Consensus' does not significantly change the other marginal effects nor does it reduce the Pseudo $\mathrm{R}^{2}$.
} 
influenced by the degree of consensus achieved in the shadow committee. When there is a considerable deal of consensus in the SGC, the likelihood of disagreement with the GC declines. One interpretation is that when overall economic signals are clear, presumably conducive to greater consensus, both committees are more inclined to make the same policy recommendation. The SGC is also found to be more activist than its $G C$ counterpart since proposed hikes and cuts decrease the likelihood of the GC matching the SGC's proposal. In contrast, larger proposals increase the likelihood of both committees agreeing about the preferred interest rate level. Finally, the share of professionals on the committee is negatively related to the likelihood of producing a recommendation that both the GC and SGC would agree with. This is an indication that the SGC's more dovish stance is likely driven by the large share of professional economists on that committee.

\section{Conclusions}

This paper addresses how shadow monetary policy committees perform in relation to their statutorily mandated counterparts with a focus on the BoE and the ECB. Three sets of tests are considered. First, we estimate Taylor (1993)-type rules for the shadow committees and central banks and compare them. Second, we examine the determinants of consensus within a shadow committee. Finally, we consider sources of disagreement between the policy rate recommendations and subsequent settings by the actual monetary policy committees.

Our salient conclusions are as follows. First, there exist subtle but systematic differences between shadow and actual committee decisions. The ECB's Shadow Governing Council tends to be relatively less inflation averse and more activist than the Governing Council. In contrast, the shadow committee of the BoE proposes a more hawkish monetary policy stance in terms of interest rate setting and quantitative easing than the Monetary Policy Committee. These differences between the shadow councils and the actual committees are particularly visible since 2011 and in the real time data.

Two factors might help to explain these differences. On the one hand, there could be ideological differences between the shadow councils and the actual committees. For instance, some members of the SMPC tend to have monetarist leanings and, therefore, the committee 
might be on average more inflation-averse than the MPC. In contrast, the Handelsblatt, a financial newspaper is well known to favor a looser monetary policy stance than actually adopted by the ECB. The latter fact might also explain why, in contrast to the SMPC, there are relatively more professional economists on the shadow council. On the other hand, differences in the loss functions between the shadow councils and the actual committee could also play an important role. ${ }^{36}$ This is especially true in case of the ECB where the SGC considers that an inflation objective of two percent with a symmetric tolerance as more appropriate than the GC's asymmetric inflation objective.

Second, we find that consensus within a committee is far easier to reach when there is no pressure to change the policy rate. In contrast, rises or falls in policy rates negatively affect consensus. Furthermore, changes in the degree of consensus are apparent when the results are disaggregated according to whether the committee members are professional or academic economists.

Third, whereas we are unable to explain differences in policy rate recommendations between the shadow and formal committees of the BoE based on observable characteristics at our disposal, the same result does not carry over to the case of the ECB. Indeed, we report strong evidence that the SGC is more activist than its GC counterpart. However, a larger degree of consensus within the SGC and a larger share of professional economists in the SGC bring about a greater (smaller) likelihood that the two committees will agree. The nationality of SGC members does not play a significant role. At the risk of exaggerating the importance of this result, this finding may have implications for current and future governance challenges faced by the ECB and the functioning of monetary policy committees more generally.

\footnotetext{
${ }^{36}$ Note that different loss functions could also be a consequence of ideological differences.
} 


\section{References}

Arnold, I.J.M. (2006), "Optimal Regional Biases in ECB Interest Rate Setting", European Journal of Political Economy 22: 307-21.

Berk, J.M., B. Bierut and E.E. Meade (2010), "The Dynamic Voting Patterns of the Bank of England's MPC", DNB Working Paper 261.

Chappell, H.W., T.M. Havrilesky and R.R. McGregor (2000), "Monetary Policy Preferences of Individual FOMC Members: A Content Analysis of the Memoranda of Discussion", Review of Economics and Statistics 79: 454-60.

Clarida, R. (2001), "The Empirics of Monetary Policy Rules in Open Economies", International Journal of Finance and Economics 6: 215-23.

Clarida, R. (2012), "What Has-and Has Not-Been Learned about Monetary Policy in a LowInflation Environment? A Review of the 2000s", Journal of Money, Credit and Banking 44 (Supplement): 123-40.

Clarida, R., J. Gali and M. Gertler (1998), "Monetary Policy Rules in Practice: Some International Evidence", European Economic Review 42: 1033-67.

Croushore, D. (2011), "Frontiers of Real-Time Data Analysis", Journal of Economic Literature 49: 72-100.

Collins, S. and P. Siklos (2004), "Optimal Monetary Policies and Inflation Targets: Are Australia, Canada and New Zealand Different from the US?" Open Economies Review 15: 347-62.

Gerlach, S. (2007), "Interest Rate Setting by the ECB, 1999-2006: Words and Deeds", International Journal of Central Banking 3: 1-45.

Gorter, J., J. Jacobs and J. de Haan (2008), "Taylor Rules for the ECB using Expectations Data," Scandinavian Journal of Economics 110: 473-88.

Fourcans, A. and R. Vranceanu (2004), "The ECB Interest Rate Rule under the Duisenberg Presidency", European Journal of Political Economy 20: 579-95.

Hodrick, R. and E. Prescott (1997), "Postwar U.S. Business Cycles: An Empirical Investigation", Journal of Money, Credit and Banking 29: 1-16.

Huber P. (1967), "The Behavior of Maximum Likelihood Estimates Under Non-standard Conditions", Proceedings of the Fifth Berkeley Symposium on Mathematical Statistics and Probability 1: 221-33.

Koo, J., I. Paya and D. Peel (2012), "The Decisions of the Shadow Monetary Policy Committee and the Monetary Policy Committee since 2002", Economic Affairs 32: 91-93. 
Meltzer, A. (2000), "The Shadow Open Market Committee: Origins and Operations", Journal of Financial Services Research 18: 119-28.

Moutot, P., A. Jung and F.P. Mongelli (2008), "The Workings of the Eurosystem - Monetary Policy Preparations and Decision-Making-Selected Issues", ECB Occasional Paper 79.

Newey, W. and K. West (1987), "A Simple, Positive Semi-definite, Heteroskedasticity and Autocorrelation Consistent Covariance Matrix", Econometrica 55, 703-8.

Orphanides, A. (2001), "Monetary Policy Rules Based on Real Time Data", American Economic Review 91: 964-85.

Poole, W., R. Rasche and D. Wheelock (2011), "The Great Inflation: Did the Shadow Know Better?" NBER Working Paper 16910.

Poole, W. (2006), "The Fed's Monetary Policy Rule", Review of the Federal Reserve Bank of St. Louis 88: 1-12.

Sauer, S. and J.-E. Sturm (2007), "Using Taylor Rules to Understand European Central Bank Monetary Policy", German Economic Review 8: 375-98.

Sibert, A. (2006), “Central Banking BY Committee”, International Finance 9 (2): 145-168.

Siklos, P. and M. Bohl (2009), "Asset Prices as Indicators of Monetary Policy: An Empirical Assessment of their Role in a Taylor Rule", Open Economies Review 20: 39-59.

Siklos, P. and M. Neuenkirch (2013), "The Monetary Policy Council and the Governing Council: Two Peas in a Pod? Mimeo.

Smith, D. (2007), "Cracks in the Foundation? A Review of the Role and the Functions of the Bank of England After 10 Years of Operational Independence", Economic Research Council Research Paper No. 23.

Sturm, J.-E. and J. de Haan (2011), "Does Central Bank Communication Really Lead to Better Forecasts of Policy Decisions? New Evidence Based on a Taylor Rule Model for the ECB," Review of World Economics 147: 41-58.

Taylor, J. (1993), "Discretion versus Policy Rules in Practice", Carnegie-Rochester Conference Series on Public Policy 39: 195-214.

White, H. (1980), "A Heteroskedasticity-consistent Covariance Matrix Estimator and a Direct Test for Heteroskedasticity", Econometrica 48: 817-38. 